\title{
Elementary kinetic modeling and experimental validation of electrochemical CO oxidation on Ni/YSZ pattern anodes
}

\author{
Vitaliy Yurkiva,b,*, Annika Utz ${ }^{\mathrm{c}}$, André Weber ${ }^{\mathrm{c}}$, Ellen Ivers-Tiffée ${ }^{\mathrm{c}, \mathrm{d}}$, Hans-Robert Volpp ${ }^{\mathrm{e}}$, \\ Wolfgang G. Bessler ${ }^{\mathrm{a}, \mathrm{b}}$ \\ a German Aerospace Centre (DLR), Institute of Technical Thermodynamics, Pfaffenwaldring 38-40, 70569 Stuttgart, Germany \\ ${ }^{\mathrm{b}}$ Institute of Thermodynamics and Thermal Engineering (ITW), Universität Stuttgart, Pfaffenwaldring 6, 70550 Stuttgart, Germany \\ c Institut für Werkstoffe der Elektrotechnik (IWE), Karlsruher Institut für Technologie (KIT), Kaiserstraße 12, 76131 Karlsruhe, Germany \\ d DFG Center for Functional Nanostructures (CFN), Karlsruher Institut für Technologie (KIT), Kaiserstraße 12, 76131 Karlsruhe, Germany \\ e Institute of Physical Chemistry (PCI), Universität Heidelberg, Im Neuenheimer Feld 229, 69120 Heidelberg, Germany
}

\section{A R T I C L E I N F O}

\section{Article history:}

Received 15 July 2011

Received in revised form 4 November 2011

Accepted 4 November 2011

Available online $\mathrm{xxx}$

\section{Keywords:}

Solid oxide fuel cell (SOFC)

Elementary kinetic modeling

Fuel oxidation

Carbon monoxide (CO)

Pattern anode

\begin{abstract}
A B S T R A C T
Carbon monoxide (CO) is a major component in typical feed gases for solid oxide fuel cells (SOFC). This paper presents a combined modeling and experimental analysis of electrochemical CO oxidation on $\mathrm{Ni} / Y S Z$ patterned model anodes. A computational model representing the coupled behavior of heterogeneous chemistry and electrochemistry in terms of elementary reactions is developed, which allows for a quantitative description of electrochemical impedance spectra and current-voltage behavior. Excellent agreement between model and experiment was achieved for the complete experimental data set, which covers a wide range of $\mathrm{CO} / \mathrm{CO}_{2} / \mathrm{N}_{2}$ gas compositions $\left(4.0 \times 10^{2} \mathrm{~Pa} \leq p \mathrm{CO} \leq 5.1 \times 10^{4} \mathrm{~Pa}\right.$ and $\left.9.5 \times 10^{2} \mathrm{~Pa} \leq p \mathrm{CO}_{2} \leq 9.2 \times 10^{4} \mathrm{~Pa}\right)$ and operating temperatures $(973 \mathrm{~K} \leq T \leq 1073 \mathrm{~K})$. In the framework of the presented model a direct mechanistic interpretation of the experimentally observed electrochemical characteristics is obtained.
\end{abstract}

(c) 2011 Elsevier Ltd. All rights reserved.

\section{Introduction}

Due to their high energy conversion efficiency and low pollutant emission level, solid oxide fuel cells (SOFC) are a promising electrical power source for a variety of applications, ranging from mobile technology to stationary power plants [1]. At the high operating temperatures of SOFCs (typically around $1100 \mathrm{~K}$ ) a variety of fuels, such as $\mathrm{H}_{2}, \mathrm{CO}, \mathrm{H}_{2} / \mathrm{CO}$-rich reformate gases, and hydrocarbons, can be utilized [2]. However, although being widely investigated, the microscopic details of the electrochemical reaction mechanism of the SOFC anode, occurring at the three-phase boundary (TPB) of gas-phase, electrode, and the yttria-stabilized zirconia (YSZ) electrolyte, are not yet fully resolved [3]. This is true even for apparently simple chemical systems such as the electrochemical $\mathrm{H}_{2}$ or $\mathrm{CO}$ oxidation reactions. Yet, the knowledge of elementary kinetics of SOFC electrochemistry is important because the understanding at the fundamental level yields better predictive capability, which allows optimal design and operation of new fuel cell systems.

\footnotetext{
* Corresponding author at: German Aerospace Centre (DLR), Institute of Technical Thermodynamics, Pfaffenwaldring 38-40, 70569 Stuttgart, Germany. Tel.: +49 7116828044; fax: +49 7116862747.

E-mail address: vitaliy.yurkiv@dlr.de (V. Yurkiv).
}

There have been only few results published on Ni/YSZ SOFC anodes operating on $\mathrm{CO} / \mathrm{CO}_{2}$ mixtures. Moreover, these studies so far did not lead to a consistent picture of the electrochemical CO oxidation mechanism. There are both qualitative (based on electrochemical measurements) and quantitative (based on kinetic modeling) mechanistic interpretations, both of which will be briefly reviewed in the following.

Holtappels et al. [4] investigated the CO electrochemical oxidation on $\mathrm{Ni} / \mathrm{YSZ}$ cermet anodes. They showed that the rate of $\mathrm{CO}$ oxidation is lower than the rate of $\mathrm{H}_{2}$ oxidation by about one order of magnitude, which was attributed to a difference in both, mass-transfer and charge-transfer resistance. They also observed that $\mathrm{CO}$ oxidation is highly dynamical. These observations were attributed to a fundamental difference in the mechanisms of $\mathrm{H}_{2}$ and $\mathrm{CO}$ oxidation. Boulenouar et al. [5] studied $\mathrm{CO}$ oxidation on a $\mathrm{Ni}$ grid electrode using electrochemical impedance spectroscopy. The experiments showed at least two relaxation times for high $p \mathrm{CO}_{2} / p \mathrm{CO}$ ratios and a single relaxation time at low $p \mathrm{CO}_{2} / p \mathrm{CO}$ ratios. Based upon equivalent circuit analysis it was concluded that $\mathrm{CO}, \mathrm{O}$ and $\mathrm{CO}_{2}$ participate in the reaction mechanism, where two species are adsorbed on a surface. Sukeshini et al. [6] carried out a series of $\mathrm{CO}$ oxidation measurements for Ni/YSZ pattern anodes. It was concluded that at low overpotentials, the rate-controlling process may likely not depend on temperature and may be $\mathrm{CO}$ 
adsorption/desorption. However, at high overpotentials a similar mechanism as for $\mathrm{H}_{2}$ oxidation may become rate-controlling.

Although the results discussed so far are of great importance as qualitative observations, they do not provide sufficient insight for a quantitative analysis. Detailed quantitative studies were performed by Lauvstad et al. [7,8] who conducted electrochemical steady-state polarization and impedance measurements for point-shaped Ni electrodes. In a theoretical analysis, different mechanisms of $\mathrm{CO}$ oxidation were compared. Based upon impedance analysis, a mechanism was identified in which $\mathrm{CO}$ adsorbed on Ni reacts with oxygen atoms adsorbed on Ni to produce gaseous $\mathrm{CO}_{2}$. This mechanism is very similar to the one proposed in a pioneer study by Etsell and Flengas [9] for the Pt/YSZ system. Etsell et al. concluded that either gaseous or adsorbed $\mathrm{CO}$ and gaseous $\mathrm{CO}_{2}$ are directly involved in the electrochemical step of the reaction. Moyer et al. [10] performed combined experimental and modeling studies for reversible solid-oxide cells with $\mathrm{Ni} / \mathrm{YSZ}$ cermet anodes operated on $\mathrm{H}_{2} / \mathrm{CO} / \mathrm{H}_{2} \mathrm{O} / \mathrm{CO}_{2}$ gas mixtures. Using elementary kinetic models, they investigated the simultaneous presence of hydrogen and oxygen spillover mechanisms. The mechanism of $\mathrm{CO}$ oxidation included $\mathrm{CO}$ and $\mathrm{CO}_{2}$ adsorption/desorption on $\mathrm{Ni}$, as well as $\mathrm{CO}$ dissociation and oxidation via a Langmuir-Hinshelwood type surface reaction on Ni. An interaction of CO with the YSZ surface was not included in this mechanism.

In the case of the electrochemical $\mathrm{H}_{2}$ oxidation, we have in the past carried out combined experimental and theoretical studies using micro-patterned model anodes, which have considerably increased our understanding of this system [3,11,12]. Applying a similar methodology to CO oxidation, we have recently developed an elementary kinetic reaction mechanism for the electrochemical $\mathrm{CO}$ oxidation [13]. The mechanism was validated against experimental electrochemical data (steady-state polarization curves and electrochemical impedance spectra) measured by Lauvstad et al. [7] for a Ni-point/YSZ model anode under different $\mathrm{CO} / \mathrm{CO}_{2}$ atmospheres. In Ref. [13], a thermodynamically consistent kinetics data set could be derived for the first time, which allows for a quantitative description of $\mathrm{CO}$ adsorption/desorption, and heterogeneous CO oxidation on both the Ni and YSZ surfaces, as well as the chargetransfer reaction kinetics taking place at the TPB. However, as the electrochemical characterization experiments of Lauvstad et al. [7] were performed for a single operating temperature $(T=1149 \mathrm{~K})$ only, no information about the temperature dependence of the rate constants of the charge-transfer reactions could be obtained so far.

In the present work, our previously developed elementary reaction mechanism [13] is applied to analyze recent experiments of Utz et al. [14], which were conducted using well-defined and thoroughly characterized Ni/YSZ patterned model anodes. These experiments stand for the most complete data set available at present and cover an extended range of operating temperatures $(973 \mathrm{~K} \leq T \leq 1073 \mathrm{~K})$ and $\mathrm{CO} / \mathrm{CO}_{2}$ gas compositions $\left(4.0 \times 10^{2} \mathrm{~Pa} \leq p \mathrm{CO} \leq 5.1 \times 10^{4} \mathrm{~Pa}\right.$ and $\left.9.5 \times 10^{2} \mathrm{~Pa} \leq p \mathrm{CO}_{2} \leq 9.2 \times 10^{4} \mathrm{~Pa}\right)$. The experimentally observed electrochemical behavior is interpreted in terms of microscopic heterogeneous reaction pathways on both $\mathrm{Ni}$ and YSZ and charge transfer steps taking place at the TPB.

\section{Theoretical and experimental methodology}

\subsection{Modeling and simulation}

Numerical simulations of the CO electrochemical oxidation were performed using the software package DENIS $[12,15,16]$, which is based on (i) an elementary kinetic approach for the thermodynamically consistent description of electrochemistry and heterogeneous surface chemistry, (ii) charge transfer reactions

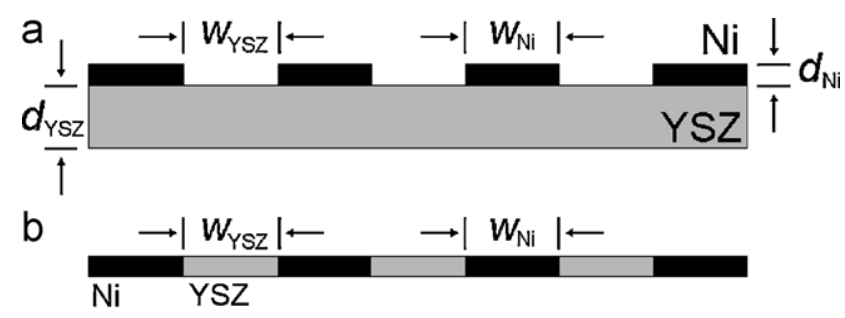

C

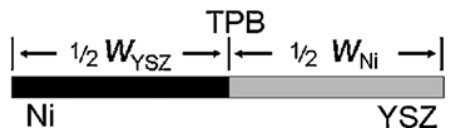

Fig. 1. Schematic representation of the Ni/YSZ patterned anode. (a) Cross section of the 3D pattern geometry; (b) representation of the 3D structure by a 1D model; (c) single repeat unit used for simulation of surface diffusion perpendicular to the TPB line.

described as surface spillover reactions at the TPB, and (iii) surface diffusion on the Ni electrode and YSZ electrolyte surfaces described in one dimensions (1D) perpendicular to the TPB line. The model reproduces one repeat unit of the pattern anode, as shown schematically in Fig. 1. The model equations are given in detail in Ref. [12]. Experimental electrochemical impedance spectra were simulated using a potential step and current relaxation technique [15]. The impedance is obtained in the frequency domain by a Fourier transformation of the resulting time-domain traces of current and potential. The differential-algebraic equation (DAE) system solver LIMEX [17] is used for the numerical integration of the reaction-diffusion equations. Chemical source terms are calculated using the DETCHEM software package [18].

The modeling framework has been used in our previous theoretical study of $\mathrm{CO}$ oxidation at a Ni/YSZ point model anode [13]. We use the reaction kinetics and thermodynamic datasets of that study (Tables 1 and 2 of Ref. [13]) as parameter base for the present work.

\subsection{Experimental}

The experimental setup and methodology has been described in detail elsewhere [14]. In the experiments, Ni/YSZ pattern anodes with an area of $10.25 \times 10.25 \mathrm{~mm}^{2}$ were used which were fabricated on $8.5 \mathrm{~mol} \%$ polycrystalline $\mathrm{Y}_{2} \mathrm{O}_{3}$-stabilized $\mathrm{ZrO}_{2}$ (YSZ) substrates. The anode consists of parallel Ni stripes with $25 \mu \mathrm{m}$ width, a spacing of $160 \mu \mathrm{m}$ and a thickness of $800 \mathrm{~nm}$. An additional Ni frame with $500 \mu \mathrm{m}$ width assures contacting of all stripes resulting in an actual TPB length of $1.3 \mathrm{~m} \mathrm{~cm}^{-2}$ in the experiments, as determined by scanning electron microscopy (SEM) measurements. The geometric features of the Ni/YSZ pattern anode used in the electrochemical characterization studies are summarized in Table 1. As counter electrode, a screen-printed Ni/YSZ cermet anode was employed, the preparation of which has been described previously [19]. The counter electrode was applied to the substrate prior to $\mathrm{Ni}$ anode patterning.

Table 1

Geometrical parameters of Ni/YSZ pattern anodes developed by Utz et al. [14] (cf. also Fig. 1).

\begin{tabular}{lll}
\hline Parameter & Symbol & Value \\
\hline Thickness of electrolyte & $d_{\mathrm{YSZ}}$ & $200 \mu \mathrm{m}$ \\
Thickness of Ni stripe & $d_{\mathrm{Ni}}$ & $0.8 \mu \mathrm{m}$ \\
Width of free YSZ area & $w_{\mathrm{YSZ}}$ & $160 \mu \mathrm{m}$ \\
Width of Ni stripe & $w_{\mathrm{Ni}}$ & $25 \mu \mathrm{m}$ \\
Length of TPB & $l_{\mathrm{TPB}}$ & $1.3 \mathrm{~m} \mathrm{~cm}^{-2}$ \\
Electrode area & $A$ & $1 \mathrm{~cm}^{2}$ \\
\hline
\end{tabular}


Electrochemical impedance spectra were recorded for different $\mathrm{CO} / \mathrm{CO}_{2} / \mathrm{N}_{2}$ gas mixtures at open circuit over a frequency range of $100 \mathrm{mHz}-1 \mathrm{MHz}$ with a voltage stimulus of $10 \mathrm{mV}$ to derive the linespecific charge transfer resistance, which will be denoted as $\mathrm{LSR}_{\mathrm{CT}}$ in the following (for further experimental details see [14] and references therein). Values of $\mathrm{LSR}_{\mathrm{CT}}$ were calculated by multiplication of the charge transfer contribution with the polarization resistance (denoted as $R_{\mathrm{CT}}$ ), the actual TPB length per electrode area $\left(l_{\mathrm{TPB}}\right)$ and the electrode area $(A)$ via:

$\mathrm{LSR}_{\mathrm{CT}}=R_{\mathrm{CT}} \times l_{\mathrm{TPB}} \times A$

The partial pressures of $\mathrm{CO}$ and $\mathrm{CO}_{2}$ were varied in the range of $4.0 \times 10^{2} \mathrm{~Pa} \leq p C O \leq 5.1 \times 10^{4} \mathrm{~Pa}$ and $9.5 \times 10^{2} \mathrm{~Pa} \leq p \mathrm{CO}_{2} \leq 9.2 \times 10^{4} \mathrm{~Pa}$, respectively. The investigated operating temperature range was $973 \mathrm{~K} \leq T \leq 1073 \mathrm{~K}$. These conditions were chosen in order to avoid $\mathrm{Ni}$ oxidation and carbon formation due to the Boudouard reaction. The stability of the $\mathrm{Ni}$ patterned anodes used in the experiments was carefully controlled by pre- and post-test SEM analysis [14].

\section{Results and discussion}

\subsection{Elementary kinetic reaction mechanism and model parameterization}

In the elementary kinetic modeling approach, the global electrochemical $\mathrm{CO}$ oxidation reaction,

$\mathrm{CO}+\mathrm{O}_{\mathrm{O}, \mathrm{YSZ}}^{\mathrm{x}} \rightleftharpoons \mathrm{CO}_{2}+V_{\mathrm{O} \mathrm{YSZ}}^{\bullet \bullet}+2 \mathrm{e}_{\mathrm{Ni}}^{-}$

is resolved into elementary steps taking place on the involved surfaces. The reaction mechanism is listed in Table 3 and schematically depicted in Fig. 2. The thermodynamic data of all involved species, which form the basis for a thermodynamically consistent kinetic model, are given in Table 2 . The mechanism contains two gas-phase species $\left(\mathrm{CO}, \mathrm{CO}_{2}\right)$, four $\mathrm{Ni}$ surface species $\left(\square_{\mathrm{Ni}}, \mathrm{CO}_{\mathrm{Ni}}, \mathrm{CO}_{2, \mathrm{Ni}}, \mathrm{O}_{\mathrm{Ni}}\right)$, five YSZ surface species $\left(\square_{\mathrm{YSZ}}, \mathrm{CO}_{\mathrm{YSZ}}, \mathrm{O}_{\mathrm{YSZ}}, \mathrm{O}_{\mathrm{YSZ}}^{1-}, \mathrm{O}_{\mathrm{YSZ}}^{2-}\right.$ ) and two YSZ bulk species $\left(\mathrm{O}_{\mathrm{O} Y S Z}^{\mathrm{X}}\right.$ and $V_{O Y S Z}^{\bullet}$, which in Kröger-Vink notation [20] stand for bulk YSZ oxygen ions and vacancies, respectively). The species denoted as $\square$ YSZ and $\square_{\mathrm{Ni}}$ represent free surface adsorption sites on YSZ and Ni.

The thermal heterogeneous reaction mechanism for the Ni surface includes $\mathrm{CO}$ and $\mathrm{CO}_{2}$ adsorption/desorption (Table 3, (R1) and (R2)) as well as CO oxidation steps via an Eley-Rideal (ER) reaction step (R3) and via a Langmuir-Hinshelwood (LH) reaction step (R4). In our previous work [13] we observed that for a consistent simula-

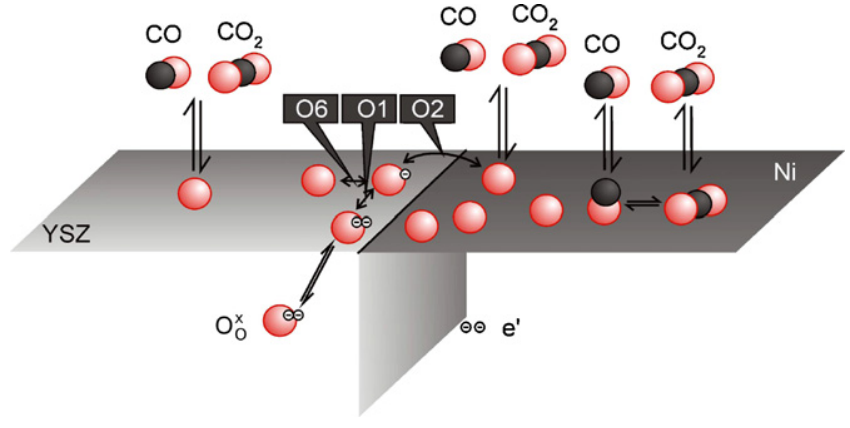

Fig. 2. Schematic illustration of the elementary surface reaction mechanism and the different charge-transfer reaction steps ((O1), (02) and (06), following the nomenclature of Refs. [12,13]) taking place at the three-phase boundary of $\mathrm{Ni}$, YSZ and gas phase. See Table 3 for a detailed list of all reactions.

Table 2

Thermodynamic data (enthalpies and entropies) for gas-phase, surface and bulk species at $T=1073 \mathrm{~K}$. The symbols $\square_{\mathrm{Ni}}$ and $\square$ Ysz denote a free surface site on Ni and YSZ, respectively.

\begin{tabular}{lrrl}
\hline Species, $i$ & $h_{i}\left(\mathrm{~kJ} \mathrm{~mol}^{-1}\right)$ & $s_{i}\left(\mathrm{~J} \mathrm{~K}^{-1} \mathrm{~mol}^{-1}\right)$ & Ref. \\
\hline Gas & & & \\
$\mathrm{CO}$ & -86 & 236 & {$[31]$} \\
$\mathrm{CO}_{2}$ & -356 & 273 & {$[31]$} \\
$\mathrm{O}_{2}$ & 25 & 246 & {$[31]$} \\
$\mathrm{Ni}$ surface & & & \\
$\square_{\mathrm{Ni}}$ & 0 & 0 & Reference species $[12,13]$ \\
$\mathrm{CO}_{\mathrm{Ni}}$ & -197 & 193 & {$[13]$} \\
$\mathrm{CO}_{2, \mathrm{Ni}}$ & -384 & 205 & {$[13]$} \\
$\mathrm{O}_{\mathrm{Ni}}$ & -222 & 39 & {$[13]$} \\
$\mathrm{O}_{\mathrm{Ni}}^{1-}$ & -222 & 39 & Set to same value as $\mathrm{O}_{\mathrm{Ni}}$ \\
$\mathrm{YSZ}^{1-}$ & & & \\
$\square_{\mathrm{YSZ}}$ & 0 & 0 & Reference species $[12,13]$ \\
$\mathrm{CO}_{\mathrm{YSZ}}$ & -159 & 172 & {$[13]$} \\
$\mathrm{O}_{\mathrm{YSZ}}^{2-}$ & -236 & 0 & {$[13]$} \\
$\mathrm{O}_{\mathrm{YSZ}}^{1}$ & -236 & 0 & Set to same value as $\mathrm{O}_{\mathrm{YSZ}}^{2-}$ \\
$\mathrm{Bulk}$ & & & \\
$V_{\mathrm{OYSZ}}^{*}$ & 0 & 0 & Reference species $[12,13]$ \\
$\mathrm{O}_{\mathrm{O} \text { YSZ }}^{\mathrm{X}}$ & -236 & 0 & {$[13]$} \\
\hline & & & \\
\hline
\end{tabular}

tion of the high and low CO partial-pressure regimes, the addition of the ER pathway (R3) to the LH pathway (R4) was necessary. This can be rationalized because under low $\mathrm{CO}$ partial pressure the actual $\mathrm{CO}$ surface coverage is very low, which leads to a substantial decrease in the $\mathrm{LH}$ reaction rate. Under these conditions only an ER reaction,

Table 3

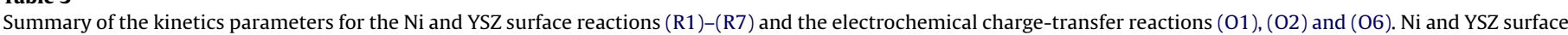

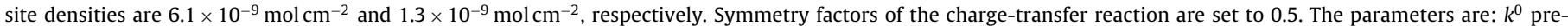

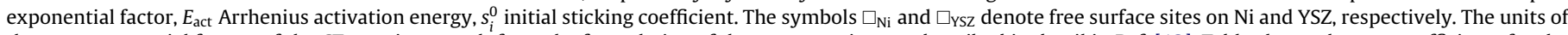

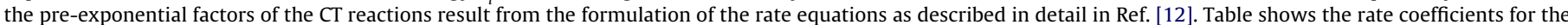
forward reactions only. The coefficients of the reverse reaction follow from thermodynamic consistency using the data in Table 2 ..

\begin{tabular}{|c|c|c|c|}
\hline Reaction & $k^{0}\left(\right.$ or $\left.s_{i}^{0}\right)$ & $E^{\text {act }}\left(\mathrm{kJ} \mathrm{mol}^{-1}\right)$ & Ref. \\
\hline \multicolumn{4}{|l|}{ Ni surface reactions } \\
\hline $\mathrm{CO}+\square_{\mathrm{Ni}} \rightleftharpoons \mathrm{CO}_{\mathrm{Ni}}$ & $s_{i}^{0}=5.0 \times 10^{-1}$ & 0 & {$[13]$} \\
\hline $\mathrm{CO}_{2, \mathrm{Ni}} \rightleftharpoons \mathrm{CO}_{2}+\square_{\mathrm{Ni}}$ & $7.0 \times 10^{11} \mathrm{~s}^{-1}$ & 41 & [13] \\
\hline $\mathrm{CO}+\mathrm{O}_{\mathrm{Ni}} \rightleftharpoons \mathrm{CO}_{2}+\square_{\mathrm{Ni}}$ & $1.0 \times 10^{23} \mathrm{~cm}^{2} \mathrm{~mol}^{-1} \mathrm{~s}^{-1}$ & 181.8 & {$[13,21]$} \\
\hline $\mathrm{CO}_{\mathrm{Ni}}+\mathrm{O}_{\mathrm{Ni}} \rightleftharpoons \mathrm{CO}_{2, \mathrm{Ni}}+\square_{\mathrm{Ni}}$ & $2.0 \times 10^{19} \mathrm{~cm}^{2} \mathrm{~mol}^{-1} \mathrm{~s}^{-1}$ & 123.6 & {$[13]$} \\
\hline \multicolumn{4}{|l|}{ YSZ surface reactions } \\
\hline $\mathrm{CO}+\square \mathrm{YSZ} \rightleftharpoons \mathrm{CO}_{\mathrm{YSZ}}$ & $s_{i}^{0}=4.0 \times 10^{-2}$ & 0 & [13] \\
\hline $\mathrm{CO}+\mathrm{O}_{\mathrm{YSZ}} \rightleftharpoons \mathrm{CO}_{2}+\square_{\mathrm{YSZ}}$ & $1.0 \times 10^{23} \mathrm{~cm}^{2} \mathrm{~mol}^{-1} \mathrm{~s}^{-1}$ & 115.1 & {$[13,21]$} \\
\hline $\mathrm{O}_{\mathrm{YSZ}}^{2-}+\mathrm{V}_{\mathrm{OYSZ}}^{\ddot{*}} \rightleftharpoons \mathrm{O}_{\mathrm{OYSZ}}^{\mathrm{X}}+\square_{\mathrm{YSZ}}(\mathrm{R} 7)$ & $1.6 \times 10^{22} \mathrm{~cm}^{2} \mathrm{~mol}^{-1} \mathrm{~s}^{-1}$ & 90.9 & {$[13]$} \\
\hline \multicolumn{4}{|l|}{ Charge-transfer reactions } \\
\hline $\mathrm{O}_{\mathrm{YSZ}}^{2-} \rightleftharpoons \mathrm{O}_{\mathrm{YSZ}}^{1-}+\mathrm{e}_{\mathrm{Ni}}^{-}$ & $8.4 \times 10^{2} \mathrm{~mol} \mathrm{~cm}^{-1} \mathrm{~s}^{-1}$ & 75 & Fit \\
\hline $\mathrm{O}_{\mathrm{YSZ}}^{1-}+\square_{\mathrm{Ni}} \rightleftharpoons \mathrm{O}_{\mathrm{Ni}}+\square_{\mathrm{YSZ}}+\mathrm{e}_{\mathrm{Ni}}^{-}(\mathrm{O} 2)$ & $3.5 \mathrm{~mol} \mathrm{~cm}^{-1} \mathrm{~s}^{-1}$ & 135 & Fit \\
\hline $\mathrm{O}_{\mathrm{YSZ}}^{1-} \rightleftharpoons \mathrm{O}_{\mathrm{YSZ}}+\mathrm{e}_{\mathrm{Ni}}^{-}$ & $1.4 \times 10^{-1} \mathrm{~mol} \mathrm{~cm}^{-1} \mathrm{~s}^{-1}$ & 82 & Fit \\
\hline
\end{tabular}


where gaseous CO directly reacts with the more strongly adsorbed oxygen atom species, can maintain a sufficiently high $\mathrm{CO}_{2}$ production rate. Following our previous work on Ni point electrodes, we have investigated $\mathrm{CO}$ oxidation on Ni via the ER pathway employing Density Functional Theory (DFT) [21]. In these calculations, an activation energy of $181.8 \mathrm{~kJ} \mathrm{~mol}^{-1}$ was obtained for the ER reaction step (R4).

The reaction mechanism for the YSZ surface includes CO adsorption/desorption (R5) and a heterogeneous CO oxidation step (R6). According to temperature-programmed desorption (TPD) experiments [21], the CO oxidation proceeds predominately via an ER mechanism, where gas-phase CO directly reacts with YSZ surfaceadsorbed oxygen atoms to yield gas-phase $\mathrm{CO}_{2}$. This reaction is taken from Ref. [13] with modified kinetics according to the DFT results given in Ref. [21]. The transport of bulk oxygen species to the YSZ surface occurs by a bulk-surface migration process via electrolyte vacancies (Table 2, (R7)).

The model includes diffusion of the $\mathrm{CO}, \mathrm{CO}_{2}$ and $\mathrm{O}$ surface species on $\mathrm{Ni}$ and YSZ perpendicular to the TPB. We use values for the diffusion coefficients from our previous work [13] of $D\left(\mathrm{CO}_{\mathrm{Ni}}\right)=D\left(\mathrm{CO}_{2 \mathrm{Ni}}\right)=4.7 \times 10^{-7} \mathrm{~cm}^{2} \times \mathrm{s}^{-1}$, $D\left(\mathrm{O}_{\mathrm{Ni}}\right)=1.3 \times 10^{-5} \mathrm{~cm}^{2} \times \mathrm{s}^{-1}$, and $D\left(\mathrm{O}_{\mathrm{YSZ}}\right)=2.3 \times 10^{-11} \mathrm{~cm}^{2} \times \mathrm{s}^{-1}$, all values at $1073 \mathrm{~K}$. It should be noted that at this temperature the nickel atoms themselves are mobile with common pre-exponential factor of $1.4 \times 10^{-2} \mathrm{~cm}^{2} \times \mathrm{s}^{-1}$ and an activation energy $93.2 \mathrm{~kJ} \mathrm{~mol}^{-1}$ [22]. The pre-exponential factor for bulk ion conductivity of the YSZ electrolyte was set to $3.6 \times 10^{7} \mathrm{~S} \mathrm{~K} \mathrm{~m}^{-1}$ with an activation energy of $90 \mathrm{~kJ} \mathrm{~mol}^{-1}$ [13].

The charge-transfer (CT) mechanism derived in the present study comprises three CT reaction steps (denoted as (O1), (O2) and (06) in Fig. 2 and Table 3), all of which take place at the TPB line. The CT reaction nomenclature follows that of our previous work on electrochemical $\mathrm{H}_{2}$ and $\mathrm{CO}$ oxidation at $\mathrm{Ni} / \mathrm{YSZ}$ anodes, where five different (01-05) CT reaction steps were investigated [12,13]. As described in detail in Ref. [13], only the reaction sequence (01) followed by $(\mathrm{O} 2)$ (denoted as (O1) and (O2)) resulted in a quantitative agreement with the point electrode experimental data of Lauvstad et al. [7]. In this reaction sequence, the first reaction (01) represents a single electron oxidation step of an $\mathrm{O}_{\mathrm{YSZ}}^{2-}$ species, followed by a second CT reaction (O2), which represent a spillover of an $\mathrm{O}_{\mathrm{YSZ}}^{1-}$ ion onto the $\mathrm{Ni}$ electrode surface with a simultaneous electron transfer to the $\mathrm{Ni}$. The additional CT reaction step (06), introduced in the present simulation study describes the discharge of an YSZ oxygen ion, $\mathrm{O}_{\text {YSZ }}^{1-}$, which proceeds by an electron transfer to the Ni electrode with the resulting YSZ oxygen atom, $\mathrm{O}_{\mathrm{YSZ}}$, remaining on the YSZ electrolyte surface. The necessity for the implementation of the additional $\mathrm{CT}$ reaction (06) will be rationalized below. The charge-transfer symmetry factor $(\beta)$ is assumed to be 0.5 for all CT reactions. Although the modeling results are sensitive to the values of the symmetry factors, we decided to fix them to the "symmetric" value of 0.5 in order to reduce the number of fitting parameters. However, if further molecular-level details about the CT mechanism become available (such as the actual location of the transition state - closer to the reagent or closer to the product side), the refinement of the symmetry factors values might certainly be valuable.

A complex space-charge layer (electrical double layer) is present at the two-phase interface between the metal (Ni) and ionconducting oxide (YSZ) [23], leading to additional capacitive effects upon transient electrochemical characterization (e.g., impedance spectroscopy). In the present model we assume that the double layer behavior can be described as ideal parallel-plate capacitor, where the capacitance is temperature-dependent via

$C_{\mathrm{dl}}=C_{0, \mathrm{dl}}+C_{T, \mathrm{dl}} \times T$
By fitting to experimental impedance data, we obtained values of $C_{0, \mathrm{dl}}=0.25 \mathrm{~F} \mathrm{~m}^{-2}$ and $C_{T, \mathrm{dl}}=8 \times 10^{-4} \mathrm{~F} \mathrm{~K}^{-1} \mathrm{~m}^{-2}$. At $T=1073 \mathrm{~K}$, the obtained double layer capacitance has a value of $1.1 \mathrm{~F} \mathrm{~m}^{-2}$. This value is somewhat lower than the value of $3.46 \mathrm{~F} \mathrm{~m}^{-2}$ observed for pattern anodes in $\mathrm{H}_{2} / \mathrm{H}_{2} \mathrm{O}$ atmospheres [3]. The difference between the capacitances for these two reaction systems might be due to the high $\mathrm{H}_{2} \mathrm{O}$ solubility in YSZ bulk [24-26], which can result in additional chemical capacitances in case of the $\mathrm{H}_{2}$ system as compared to the CO system. For an ideal capacitor, the thickness $d$ of the interfacial double layer can be estimated via

$d=\frac{\varepsilon \varepsilon_{0}}{C_{\mathrm{dl}}}$

where $\varepsilon_{0}$ is the vacuum permittivity $\left(8.85 \times 10^{-12} \mathrm{Fm}^{-1}\right), \varepsilon$ is a dielectric constant $(\varepsilon=27$ as obtained for bulk YSZ measured by Fork et al. [27]). Applying the values given above, we obtain $d=0.21 \mathrm{~nm}$ for $\mathrm{CO} / \mathrm{CO}_{2}$ and $d=0.068 \mathrm{~nm}$ for $\mathrm{H}_{2} / \mathrm{H}_{2} \mathrm{O}$. Both values are smaller than the YSZ lattice parameters $(a=0.36 \mathrm{~nm}, c=0.518 \mathrm{~nm})$. As already pointed out by Vels Hansen et al., such low values have no direct physical meaning and additional capacitances in parallel need to be assumed in order to interpret the measured capacitance values [28].

\subsection{Electrochemical impedance spectra}

Fig. 3 shows the comparison between experimental and simulated impedance spectra for four different conditions (varying $p \mathrm{CO}$ and $p \mathrm{CO}_{2}$ ) at $T=1073 \mathrm{~K}$. For each condition, both Nyquist plots (upper panels - a1, b1, c1, d1) and Bode plots (lower panels a2, b2, c2, d2) are shown. We observe a qualitative agreement between model and experiment over the complete investigated range of experimental conditions. The quantitative discrepancy (rel. error $<5 \%$ ) needs to be considered as minor given the physical basis of the present model. Note that all simulations are based on one single parameter set. In contrast, equivalent circuit models usually show an excellent agreement with experimental data, however they are based upon fitting several parameters for each individual condition.

The polarization resistance obtained from the impedance spectra shown in Fig. 3 ( $R_{\mathrm{CT}}$ in Eq. (1)) was used to calculate $\mathrm{LSR}_{\mathrm{CT}}$, which will be discussed in the following sections.

\subsection{Influence of $\mathrm{CO} / \mathrm{CO}_{2}$ gas-phase composition}

Previous studies on model anodes have shown that gas-phase composition has a strong influence on the electrochemical performance, for both $\mathrm{H}_{2}$ [3,29] and $\mathrm{CO}$ [13] oxidation. Fig. 4 shows a comparison between experimental and simulated values for $\mathrm{LSR}_{\mathrm{CT}}$ (open symbols) as a function of $\mathrm{CO}$ and $\mathrm{CO}_{2}$ partial pressures for an operating temperature of $1073 \mathrm{~K}$. The LSR $_{\mathrm{CT}}$ shows a pronounced dependence on both $\mathrm{CO}$ and $\mathrm{CO}_{2}$ partial pressures. Generally, increasing either $\mathrm{CO}$ or $\mathrm{CO}_{2}$ partial pressure decreases $\mathrm{LSR}_{\mathrm{CT}}$ and therefore enhances the electrode kinetics. A particular interesting case is the $p \mathrm{CO}$ variations at low $p \mathrm{CO}_{2}$ shown in Fig. 4a. Here, LSR $_{\mathrm{CT}}$ shows different slopes at high and low $p$ CO values and a broad minimum at $p \mathrm{CO} \sim 10^{4} \mathrm{~Pa}$. The minimum is also present for higher $p \mathrm{CO}_{2}$, as seen in Fig. $4 \mathrm{~b}$, however, shifted towards higher pCO.

The observation that both reactant and product concentrations positively influence the electrode kinetics is non-intuitive. A similar behavior is known from the $\mathrm{H}_{2} / \mathrm{H}_{2} \mathrm{O} / \mathrm{Ni} / \mathrm{YSZ}$ model anode system, where both increasing hydrogen and water partial pressure increases the electrode kinetics $[3,30]$. We have showed before that this effect is due to the combined changes of concentration and electrode potential [3]. 

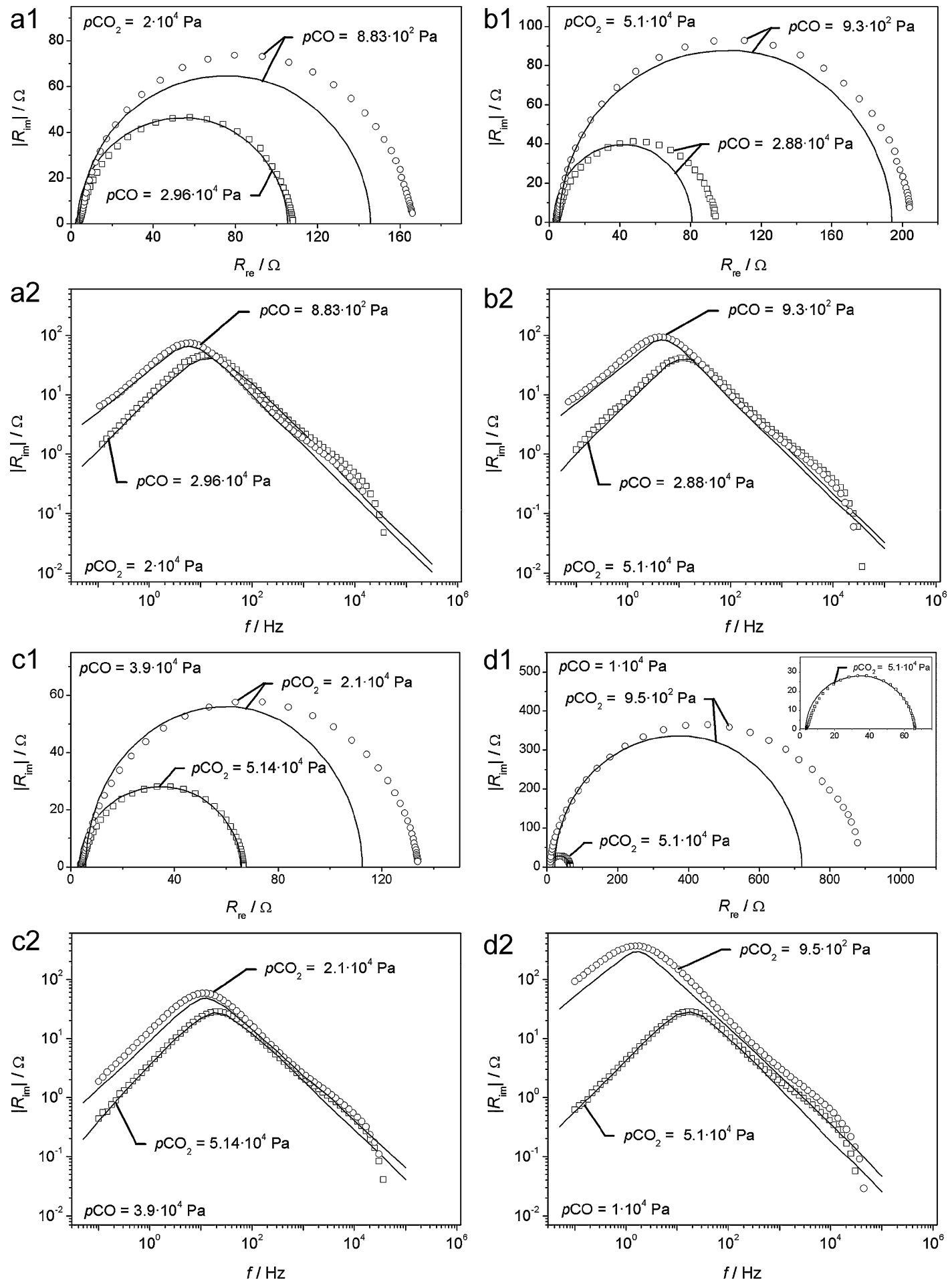

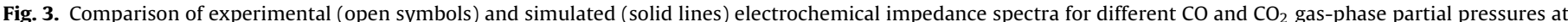

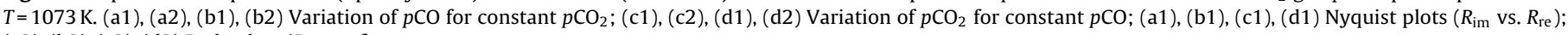
(a2), (b2), (c2), (d2) Bode plots ( $R_{\mathrm{im}}$ vs. $f$ ).

Simulation results for the full mechanism ((O1), (02) and (O6), cf. Fig. 2), parameterized as given in Table 3, are shown as solid lines in Fig. 4. The simulations agree quantitatively with the experiments over the complete investigated range of $\mathrm{CO}$ and $\mathrm{CO}_{2}$ partial pressures. This agreement is the basis for the model-based mechanistic interpretation below (Section 3.5). It should be noted that simulations based on the previously derived (O1) and (O2) consecutive CT reaction mechanism only (cf. Fig. 2 ), the experimentally observed minimum in $\mathrm{LSR}_{\mathrm{CT}}$ could not be reproduced; only the high $\mathrm{CO}$ partial pressure region could be quantitatively described. This finding motivated the introduction of the additional CT reaction (06).

\subsection{Influence of temperature}

The temperature dependence of $\mathrm{LSR}_{\mathrm{CT}}$ was measured and simulated for two different $\mathrm{CO}$ partial pressures of $p \mathrm{CO}=3 \times 10^{4} \mathrm{~Pa}$ 

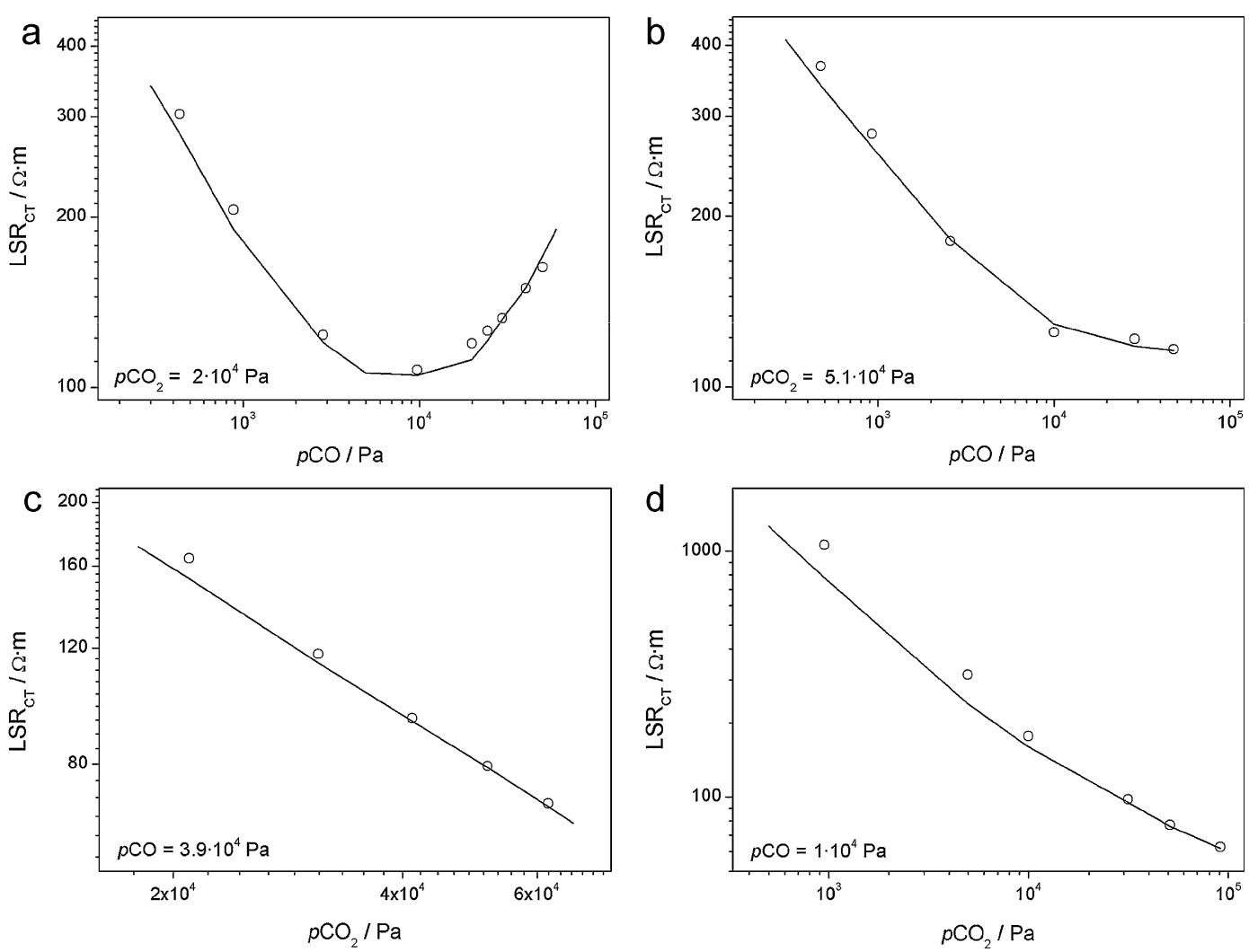

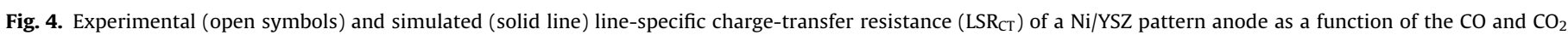
gas-phase partial pressures at $T=1073 \mathrm{~K}$. (a and b) Variation of $p \mathrm{CO}$ for constant $p \mathrm{CO}_{2}$; (c and d) variation of $p \mathrm{CO}_{2}$ for constant $p C \mathrm{CO}$.

and $p \mathrm{CO}=9.2 \times 10^{2} \mathrm{~Pa}$ at a constant $\mathrm{CO}_{2}$ partial pressure of $p \mathrm{CO}_{2}=2 \times 10^{4} \mathrm{~Pa}$. These measurements form the basis of quantifying the activation energies of the charge transfer reactions (Table 3), which was not possible in previous work due to lacking temperature-dependent data [13]. The comparison between simulation (lines) and experimental results (open symbols) is shown in Fig. 5. The data show an Arrhenius-type temperature dependence with an activation energy that depends on $p C O$. Both the absolute values and the slope of the simulated LSR $_{\mathrm{CT}}$ curves are in excellent agreement with the experimental data. This demonstrate the ability of (01), (O2) and (O6) CT mechanism to reproduce the electrochemical data over the entire $\mathrm{CO} / \mathrm{CO}_{2}$ gas composition and operating temperature range investigated experimentally.

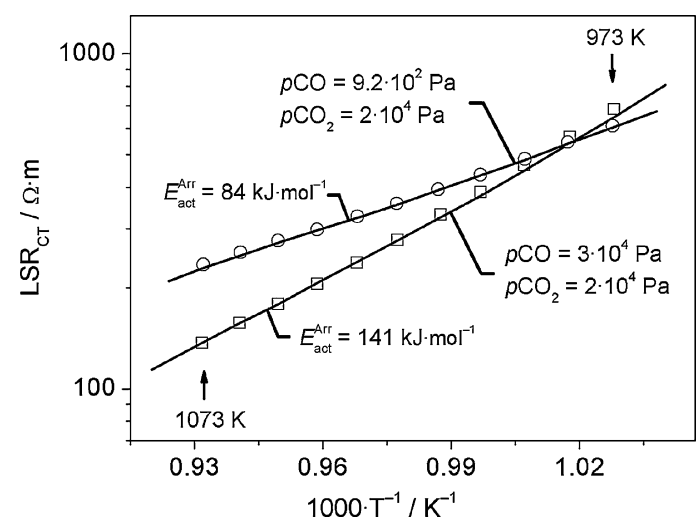

Fig. 5. Experimental (open symbols) and simulated (lines) line-specific chargetransfer resistance ( $\mathrm{LSR}_{\mathrm{CT}}$ ) versus inverse temperature for two different gas-phase compositions. $E_{\text {act }}^{\text {Arr }}$ - activation energy calculated based upon curves slope.
Fig. 5 also depicts the global activation energies for two cases at high and at low $p \mathrm{CO}$, determined from the slope of the experimental data. They have values of $141 \mathrm{~kJ} \mathrm{~mol}^{-1}$ and $84 \mathrm{~kJ} \mathrm{~mol}^{-1}$, respectively. The activation energies of the elementary charge-transfer steps (cf. Table 3 ) are very similar to these global activation energies. This finding confirms the change of rate-determining step for different $p C O$ (see following section). Note that the globally observed activation energies are a convolution of the thermal activation of the different chemical and physical processes contributing to the polarization behavior.

\subsection{Sensitivity analysis and mechanistic interpretation}

In order to determine the influence of different physicochemical processes on the electrode performance, a sensitivity analysis was performed. In a sensitivity analysis, model parameters $P$ are individually varied by $10 \%$, and the impact on the $L_{S R}$ is quantified as dimensionless relative sensitivity, $s=\left(\Delta \mathrm{LSR}_{\mathrm{CT}} / \mathrm{LSR}_{\mathrm{CT}}\right) /(\Delta P / P)$. A sensitivity of unity means that LSR $_{C T}$ is directly proportional to the parameter. Negative sensitivities mean that a parameter increase leads to a decrease of $\mathrm{LSR}_{\mathrm{CT}}$. Sensitivities close to zero mean that the process represented by that parameter is not rate-determining.

This analysis was carried out for two different gas compositions representing conditions left and right of the $\mathrm{LST}_{\mathrm{CT}}$ minimum shown in Fig. 4a. Results are shown in Fig. 6. The parameters are separated into three blocks. The upper block describes kinetic parameters of all chemical and electrochemical reactions, the middle part includes the description of transport parameters of all surface species (diffusion coefficients) and the lower block describes the influence of physical parameters (TPB length, pressure and temperature). The change of heterogeneous reactions kinetics on both $\mathrm{Ni}$ and YSZ surfaces does not significantly influence $\mathrm{LSR}_{\mathrm{CT}}$, 


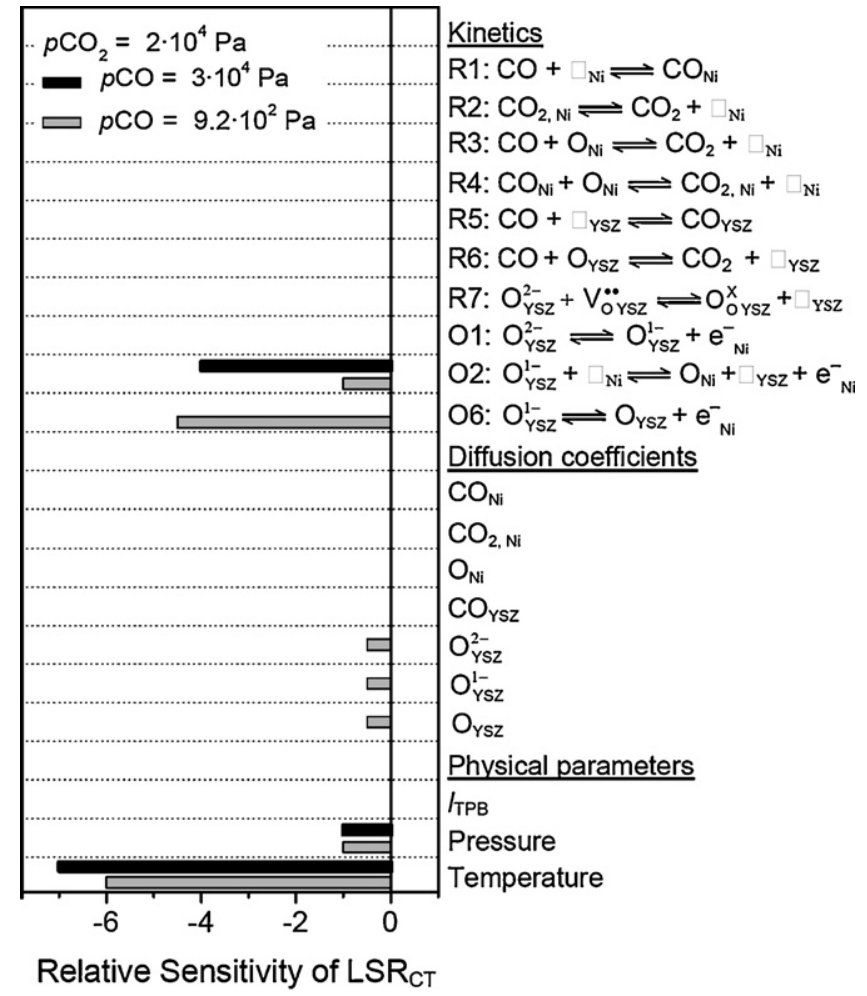

Fig. 6. Sensitivity of the line specific resistance $\left(\mathrm{LSR}_{\mathrm{CT}}\right)$ on model parameters for temperature of $1073 \mathrm{~K}$ and two different $p \mathrm{CO}$ at $p \mathrm{CO}_{2}=2 \times 10^{4} \mathrm{~Pa}$, representing conditions left and right of the minimum of LSR $\mathrm{CT}_{\mathrm{C}}$ shown in Fig. 4a. Negative values of the sensitivity means that an increase in parameter value decreases LSR $\mathrm{C}_{\mathrm{CT}}$.

indicating that the interaction of the gaseous components with the $\mathrm{Ni}$ and YSZ surfaces is fast and not rate-determining. The analysis reveals that the charge-transfer reactions are rate-limiting. This is not surprising as these reactions are confined to the (onedimensional) TPB line, whereas heterogeneous reactions take place at the (two-dimensional) surfaces. At low CO partial pressure $\left(p \mathrm{CO}=9.2 \times 10^{2} \mathrm{~Pa}\right)$, reaction $(\mathrm{O} 6)$ dominates the behavior with colimitation of reaction $(\mathrm{O} 2)$. Note that for this case oxygen diffusion on the YSZ surface also becomes rate co-limiting. This is a clear indication that, at low CO partial pressures, the dominant part of the conversion proceeds via (O1) and (06) mechanism with CO oxidation on the YSZ surface. When the CO partial pressure increases $\left(p \mathrm{CO}=3 \times 10^{4} \mathrm{~Pa}\right)$, the only rate-limiting step is the spillover reaction (O2), indicating that the conversion proceeds via (01) and (O2) mechanism with $\mathrm{CO}$ oxidation on the Ni surface.

Fig. 6 further shows that the LSR $_{C T}$ is strongly and nonlinearly sensitive on temperature, as is already evident from Fig. 5. The sensitivity analysis indicates that different $\mathrm{CO}$ partial pressures result in different activation energy regimes.

For further insight into the mechanistic details, calculated coverages of all species on both Ni and YSZ surfaces are shown in Fig. 7 as a function of $\mathrm{CO}$ partial pressure. These results indicate that the oxygen coverage on the $\mathrm{Ni}$ adjacent to the TPB $\left(\theta_{\mathrm{O}, \mathrm{Ni} \text {-TPB }}\right)$ is the key parameter inducing the change in the experimentally observed $\mathrm{LSR}_{\mathrm{CT}}$ slope. The value of $\theta_{\mathrm{O}, \mathrm{Ni} \text {-TPB }}$ is determined by the competition between oxygen formation at the Ni TPB region (due to the spillover $\mathrm{CT}$ reaction step $(\mathrm{O} 2)$ ) and the heterogeneous $\mathrm{O}$ removal reactions on Ni (via (R3) and (R4)), both of which depend on the $\mathrm{CO} / \mathrm{CO}_{2}$ gas composition. The present results show that at sufficiently high CO partial pressures the overall charge transfer occurs via (O1) and $(\mathrm{O} 2)$ reactions, while at low $\mathrm{CO}$ partial pressures the overall charge transfer occurs via the (01) and (O6), as the actual rate of $(\mathrm{O} 2)$ spillover step strongly decreases with increasing $\theta_{\mathrm{O}, \mathrm{Ni}-\mathrm{TPB}}$

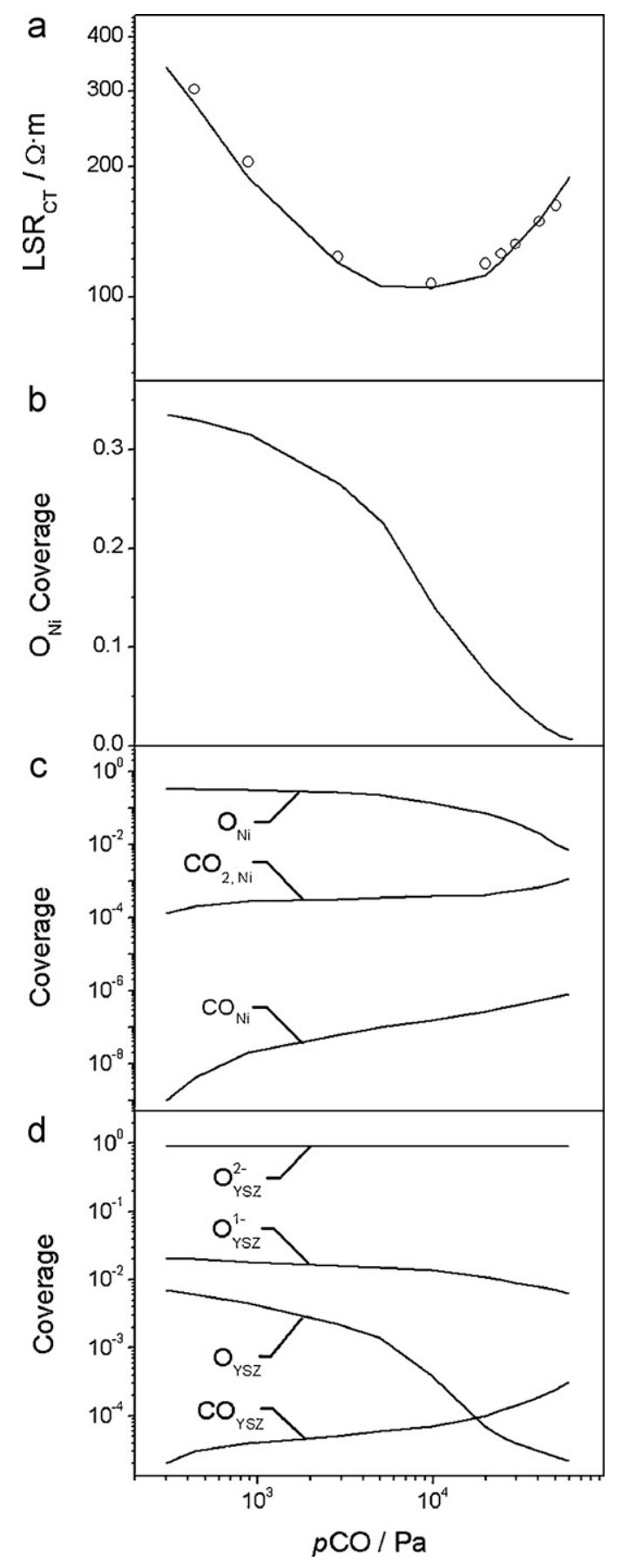

Fig. 7. Comparison of (a) $\mathrm{LSR}_{\mathrm{CT}}$ (reproduced from Fig. 4a) with surface species coverages of (b) oxygen on the Ni surface (linear scale), (c) all species on the Ni surface (logarithmic scale), (d) all species on YSZ surface as function of CO partial pressure for a $\mathrm{CO}_{2}$ partial pressure of $p \mathrm{CO}_{2}=2 \times 10^{4} \mathrm{~Pa}(T=1073 \mathrm{~K})$.

due to surface site blocking. In the framework of the extended CT reaction model, the minimum in the experimental LSR $_{C T}$ values at $T=1073 \mathrm{~K}, p \mathrm{CO}_{2}=2 \times 10^{4} \mathrm{~Pa}$ and $p \mathrm{CO}=1 \times 10^{4} \mathrm{~Pa}$ could be quantitatively reproduced in numerical simulations (Fig. 4). The simulations predict a value of $\theta_{\mathrm{O}, \mathrm{Ni}-\mathrm{TPB}}=0.15$ for these conditions (Fig. 7b).

\section{Conclusions}

We have presented a combined modeling and experimental study of electrochemical CO oxidation at SOFC Ni/YSZ anodes. An elementary kinetic model was developed and validated 
using well-defined micropatterned model anodes. By solving reaction-diffusion equations on both the $\mathrm{Ni}$ electrode and the YSZ electrolyte surfaces, experimental data were successfully reproduced over a wide range of $\mathrm{CO} / \mathrm{CO}_{2} / \mathrm{N}_{2}$ gas compositions and operating temperatures. In contrast to commonly used Butler-Volmer equations, which are based on global reaction kinetics, the representation of all chemical processes in terms of elementary reactions allows for predictive simulations of the complex behavior of Ni/YSZ patterned anodes. Furthermore, the elementary kinetic description opens up the possibility of a direct mechanistic interpretation of the experimentally observed electrochemical characteristics via sensitivity analyses and surface coverage quantifications.

The main results of this study are summarized as follows: $\mathrm{CO}$ and $\mathrm{CO}_{2}$ concentrations have a strong and nonlinear influence on the electrode kinetics. Over a wide range of gas compositions, both an increase of $\mathrm{CO}$ or $\mathrm{CO}_{2}$ partial pressure enhances the electrode kinetics. This counter-intuitive effect is due to a simultaneous change of electric potential and coverages of species participating in the charge-transfer reaction. The gas composition also influences the macroscopically observed activation energy. It was shown that charge transfer can proceed via two different mechanisms: At high $\mathrm{CO} / \mathrm{CO}_{2}$ ratios, oxygen spillover from the YSZ to the Ni surface takes place, and $\mathrm{CO}$ is oxidized in a Langmuir-Hinshelwood type heterogeneous reaction on the Ni surface. At low $\mathrm{CO} / \mathrm{CO}_{2}$ ratios, the largest part of oxygen ions is fully reduced on the YSZ surface without undergoing spillover, and $\mathrm{CO}$ is oxidized in an Eley-Rideal type heterogeneous reaction on the YSZ surface.

The level of understanding achieved in the present study will be the basis for further investigations of the behavior of more complex SOFC fuels, in particular reformate gases or hydrocarbons.

\section{Acknowledgments}

Financial support by the German Research Foundation (DFG) under grant numbers BE 3819/1-1, VO 642/2-1 and WE 4188/1-1 is gratefully acknowledged. H.-R. Volpp and V. Yurkiv would like to thank the International Graduate College (IGK 7110) "Complex Processes: Modeling, Simulation and Optimization" and the Heidelberg Graduate School of Mathematical and Computational Methods for the Sciences at the Interdisciplinary Center for Scientific Computing (IWR) for financial support. W.G. Bessler acknowledges funding by the Initiative and Networking Fund of the Helmholtz Association. Thanks are due to Dr. A. Gorski (Institute of Physical Chemistry, Polish Academy of Science, Warsaw, Poland) and Dr. M. Vogler (German Aerospace Center, Stuttgart, Germany) for many fruitful discussions, as well as Prof. D. Gerthsen and Dr. H. Störmer (KIT, Karlsruhe, Germany) for pattern anode preparation.

\section{References}

[1] S.C. Singhal, K. Kendall, High Temperature Soli Oxide Fuel Cell: Fundamentals, Design and Applications. Elsevier Science, Oxford (2003).

[2] B.C.H. Steele, Nature 400 (1999) 619.

[3] W.G. Bessler, M. Vogler, H. Störmer, D. Gerthsen, A. Utz, A. Weber, E. Ivers-Tiffée, Phys. Chem. Chem. Phys. 12 (2010) 13888.

[4] P. Holtappels, L.G.J. De Haart, U. Stimming, I.C. Vinke, M. Mogensen, J. Appl. Electrochem. 29 (1999) 561.

[5] F.Z. Boulenouar, K. Yashiro, M. Oishi, A. Kaimai, Y. Nigara, T. Kawada, J. Mizusaki, Electrochem. Soc. Ser. (2001) 759.

[6] A.M. Sukeshini, B. Habibzadeh, B.P. Becker, C.A. Stoltz, B.W. Eichhorn, G.S. Jackson, J. Electrochem. Soc. 153 (2006) A705.

[7] G.O. Lauvstad, R. Tunold, S. Sunde, J. Electrochem. Soc. 149 (2002) E506.

[8] G.O. Lauvstad, R. Tunold, S. Sunde, J. Electrochem. Soc. 149 (2002) E497.

[9] T.H. Etsell, S.N. Flengas, J. Electrochem. Soc. 118 (1971) 1890.

[10] C.J. Moyer, N.P. Sullivan, H. Zhu, R.J. Kee, J. Electrochem. Soc. 158 (2011) B117.

[11] A. Utz, H. Stormer, A. Leonide, A. Weber, E. Ivers-Tiffee, J. Electrochem. Soc. 157 (2010) B920.

[12] M. Vogler, A. Bieberle-Hütter, L. Gauckler, J. Warnatz, W.G. Bessler, J. Electrochem. Soc. 156 (2009) B663.

[13] V.Yurkiv, D. Starukhin, H.-R. Volpp, W.G. Bessler, J. Electrochem. Soc. 158(2011) B5.

[14] A. Utz, A. Leonide, A. Weber, E. Ivers-Tiffée, J. Power Sources 196 (2011) 7217.

[15] W.G. Bessler, J. Electrochem. Soc. 154 (2007) B1186.

[16] W.G. Bessler, S. Gewies, M. Vogler, Electrochim. Acta 53 (2007) 1782.

[17] P. Deuflhard, E. Hairer, J. Zugck, Numer. Math. 51 (1987) 501

[18] O. Deutschmann, S. Tischer, C. Correa, D. Chatterjee, S. Kleditzsch, V.M Janardhanan, DETCHEM Software Package, Version 2.0, Karlsruhe, 2004, http://www.detchem.com.

[19] V. Sonn, A. Leonide, E. Ivers-Tiffee, J. Electrochem. Soc. 155 (2008) B675.

[20] F.A. Kröger, H.J. Vink, in: F. Seitz, D. Turnull (Eds.), Solid State Physics - Advances in Research and Applications, Academic Press, New York, NY, 1956, p. 431.

[21] A. Gorski, V. Yurkiv, W.G. Bessler, H.-R. Volpp, ECS Trans. 35 (1) (2011) 727.

[22] M. Mogensen, S. Skaarup, Solid State Ionics 86 (1996) 1151.

[23] R.D. Armstrong, B.R. Horrocks, Solid State Ionics 94 (1997) 181.

[24] A. Gorski, V. Yurkiv, D. Starukhin, H.-R. Volpp, J. Power Sources 196 (2011) 7188

[25] M. Vogler, W.G. Bessler, ECS Trans. 25 (2009) 1957.

[26] C. Wagner, Ber. Bunsen. Phys. Chem. 72 (1968) 778

[27] D.K. Fork, D.B. Fenner, G.A.N. Connell, J.M. Phillips, T.H. Geballe, Appl. Phys. Lett 57 (1990) 1137

[28] K.V. Hansen, K. Norrman, M. Mogensen, J. Electrochem. Soc. 151 (2004) A1436

[29] D.G. Goodwin, H.Y.Zhu, A.M. Colclasure, R.J. Kee, J. Electrochem. Soc. 156 (2009) B1004.

[30] A. Bieberle, L.P. Meier, L.J. Gauckler, J. Electrochem. Soc. 148 (2001) A646.

[31] C.M.W. Chase, C.A. Davies, J.R. Downey, D.J. Frurip, D.A. McDonald, A.N. Syverud, J. Phys. Chem. Ref. 14 (1985) 